\title{
KETERLIBATAN KELUARGA DALAM KEGIATAN DI SEKOLAH DALAM PERSPEKTIF KEMITRAAN
}

\author{
${ }^{1)}$ Ihat Hatimah \\ ${ }^{1}$ Dosen Departemen Pendidikan Luar Sekolah \\ Faskultas ILmu Pendidikan Universitas Pendidikan Indonesia \\ Email: ihat hatimah.@yahoo.co.id
}

\begin{abstract}
Keluarga sebagai lembaga pendidikan yang pertama dan utama bagi seorang anak mempunya peran yang sangat besar untuk membekali anak menuju kehidupannya. Sesuai UUSPN No 20 tahun 2003, pendidikan adalah tanggung jawab bersama antara keluarga, masyarakat dan pemerintah, Pentingnya kemitraan sekolah dan keluarga adalah: 1) Keluarga adalah pendidik yang pertama dan utama, tetapi dalam praktiknya masih banyak keluarga yang menyerahkan sepenuhnya tanggung jawab pendidikan anak pada sekolah, 2) Peran sekolah adalah membantu keluarga agar pelaksanaan pendidikan lebih sistimatis, efektif, dan hasilnya tersertifikasi, 3) Tidak semua kebutuhan pendidikan anak dapat dipenuhi oleh satuan pendidikan maupun keluarga, 4) Kerjasama keluarga dengan satuan pendidikan mutlak diperlukan, 5)Satuan pendidikan wajib mendorong kemitraan dan pelibatan keluarga dalam memajukan pendidikan anak mereka. Berdasarkan berbagai hasil penelitian menunjukkan bahwa dengan adanya kolaborasi antara keluarga dan sekolah berpengaruh meningkatkan kemajuan dan kesusksesan anak-anaknya.
\end{abstract}

Kata kunci: Keluarga,kemitraan, pengaruh kolaborasi

\section{PENDAHULUAN}

Undang-Undang No 20 Tahun 2003 tentang Sistem Pendidikan Nasional (UUSPN) menjadi acuan untuk membuat kebijakan dan manajemen pendidikan pada tingkat nasional, regional, maupun di tingkat satuan pendidikan. Pendidikan Nasional bertujuan menyiapkan sumber daya manusia (SDM) yang berkualitas, memiliki kompetensi, berkarakter dan berdaya saing tinggi. Sesuai UUSPN no 20 tahun 2003, pendidikan adalah tanggung jawab bersama antara keluarga, masyarakat dan pemerintah, yang merupakan tri pusat pendidikan. Peralihan bentuk pendidikan informal (keluarga) ke pendidikan formal memerlukan kerjasama antara orang tua dan lembaga formal.

Keluarga sebagai lembaga pendidikan yang pertama dan utama bagi seorang anak mempunyai andil yang sangat besar bagi perkembangan anak untuk menuju kehidupannya yang lebih komplek. Apabila kehidupan keluarga dibina dengan baik, maka kehidupan mayarakat akan baik pula. Melalui keluarga diharapkan anak dan anggota keluarga lainnya dapat tumbuh dan berkembangbsesuai dengan kemampuannya untuk menjadi seseorang 
yang mandiri dan dapat menjadi insan yang produktif bgi dirinyan sendiri dan lingkungannya. Menurut Riana dkk. (2012 hal 3):

Keluarga memiliki peranan penting untuk memberikan dasar pendidikan, sikap serta keterampilan dasar, seperti: pendidikan agama, budi pekerti, sopan santun, estetika, kasih sayang, rasa aman, dasar-dasar untuk mematuhi peraturanperaturan, dan menanamkan kebiasaan-kebiasaan. Selain hal tersebut, keluarga memiliki kewajiban mengajarkan nilai-nilai dan tingkah laku sesuai dengan norma-norma yang berlaku di masyarakat.

Sebagai realisasi dari bentuk tanggung jawab dalam penyelenggaraan pendidikan, diperlukan adanya kerjasama yang harmonis antara keluarga, sekolah, dan masyarakat sebagai bentuk kemitraan. Hal ini sesuai dengan yang diungkapkan oleh Palupi Raraswati (2016, hal: 2), yaitu pentingnya kemitraan sekolah dengan keluarga yaitu:

1. Keluarga adalah pendidik yang pertama dan utama, tetapi dalam praktiknya masih banyak keluarga yang menyerahkan sepenuhnya tanggung jawab pendidikan anak pada sekolah

2. Peran sekolah adalah membantu keluarga agar pelaksanaan pendidikan lebih sistimatis, efektif, dan hasilnya tersertifikasi

3. Tidak semua kebutuhan pendidikan anak dapat dipenuhi oleh satuan pendidikan maupun keluarga
4. Kerjasama keluarga dengan satuan pendidikan mutlak diperlukan

5. Satuan pendidikan wajib mendorong kemitraan dan pelibatan keluarga dalam memajukan pendidikan anak mereka

\section{KAJIAN TEORETIS}

Pendidikan keluarga adalah bagian pendidikan luar sekolah yang termasuk dalam satuan-satuan pendidikan dalam system pendidikan nasional. Pendidikan keluarga adalah pendidikan yang diperoleh seseorang dengan pengalaman sehari-hari dengan sadar atau tidak sadar, sejak ia lahir sampai meninggal di dalam keluarga/pergaulannya sehari-hari. Orang tua dalam keluarga mempunyai peran yang sangat penting dalam perkembangan seorang anak, hal ini sesuai dengan yang tercantum dalam buku Riana dkk. (2012, hal 12), peran keluarga yaitu:

a. Sumber dan pemberi rasa kasih sayang.

Kasih sayang dapat merupakan alat pendidikan, sehingga dengan kasih sayang yang tulus dari keluarga, seorang anak akan merasa nyaman, terlindungi, sehingga anak akan berkembang secara maksimal secara fisik maupun mental

b. Pengasuh dan pemelihara

Orang tua mempunyai kewajiban untuk mengasuh/membimbing anak sesuai dengan pertumbuhan dan perkembangannya. Pola pengasuhan yang tepat digunakan dalam keluarga akan berdampak 
positif terhadap perkembangan anak tersebut

c. Tempat mencurahkan isi hati

Seorang anak akan merrasa nyaman untuk mencurahkan hatinya ketika orang tua mau mendengar. Orang tua harus menyediakan waktu khusus ketika anak membutuhkannya, sehingga anak akan merasa aman ketika orang tuanya bersedia setiap saat untuk menerima segala curahan hati anakanaknya

d. Mengatur kehidupan dalam rumah tangga

Orang tua mempunyai peran sebagai pengelola dalam keluarga, sehingga orang tua harus mampu melaksanakan perannya tersebut yang akhirnya dapat menumbuhkan rasa tanggung jawab pada setiap anggota keluarga sesuai dengan perannya masing-masing.

e. Pembimbing dalam hubungan pribadi

Orang tua harus mampu memerankan sebagai pembimbing untuk anak-anaknya di dalam menjalani berbagai aspek kehidupan. Orang tua harus mampu mencari solusi yang tepat ketika anak-anaknya memiki permasalahan dalam kehidupannya, sehingga orang tua dianggap dapat menjadi pembimbing utama bagi anak-anaknya

f. Pendidik dalam segi-segi emosional

Hubungan emosinal antara orang tua dengan anak tidak bisa dilepaskan begidtu saja, sehingga orang tua harus mampu menciptakan hubungan yang harmonis dalam keluarga, sehingga setiap anggota keluarga merasa saling membutuhkan.

Selanjutnya peran keluarga diperkuat oleh Palupi Raraswati (2016) yang diungkapkan dalam Seminar Nasional tentang Teori, Kebijakan dan Praktek Pendidikan Keluarga di Indonesia yaitu:

a. Menciptakan lingkungan belajar di rumah yang menyenangkan, menumbuhkan budi pekerti, dan budaya prestasi

b. Menjalin interaksi dan komunikasi yang hangat dan penuh kasih saying dengan anak

c. Memberikan motivasi yang menumuhkan rasa percaya diri pada anak

d. Menjalin hubungan aktif dengan pihak sekolah untuk menciptakan lingkungan belajar yang kondusif

e. Berpartisipasi aktif dalam kegiatan keluarga di sekolah

Menurut Megawangi (2003) ada beberapa kesalahan orang tua dalam mendidik anak-anaknya yang dapat mempengaruhi perkembangan kecerdasan emosi anak, yaitu:
a. Kurang menunjukkan ekspresi kasih sayang secara verbal maupun fisik
b. Kurang meluangkan waktu yang cukup untuk anaknya
c. Bersikap kasar secara verbal, misalnya menyindir, 
meremehkan anak, dan berkata kasar

d. Bersikap kasar secara fisik, misalnya memukul, mencubit, dan memberikan hukuman badan lainnya

e. Terlalu memaksa anak untuk menguasai kemampuan kognitif secara dini

f. Tidak menanamkan good character kepada anak

\section{METODE PENELITIAN}

Penelitian ini dilakukan melalui kajian kepustakaan terhadap sejumlah laporan tentang keterlibatan orang tua dalam penyelenggaraan pendidikan nonformal dalam hal ini pendidikan keluarga. Subjek penelitian adalah peserta didik non formal dalam bentuk pendidikan keluarga, sebagaimana dianalisis secara dokumentasi.

\section{HASIL DAN PEMBAHASAN}

Keterlibatan orang tua dalam lembaga pendidikan menurut Berger (1991, hal.122) dapat dilakukan melalui: 1) pelibatan orang tua sebagai pendidik bagi anaknya, 2) pelibatan orang tua sebagai pengamat proses pembelajaran di kelas, 3) pelibatan orang tua sebagai tenaga sukarela yang bersifat sementara, 4) menjadikan orang tua sebagai sumber tenaga sukarela, 5) menjadikan orang tua sebagai pengambil kebijakan di sekolah.

Beberapa alasan utama yang mendasari pentingnya melibatkan orang tua dalam pendidikan di lembaga pendidikan menurut Epstein (1991) dalam Brewer (2007, hal.238) adalah: 1) orang tua dan guru lebih banyak memiliki kesamaan dibandingkan perbedaan dalam mendidik anak. Mereka banyak memiliki tujuan dan kebutuhan yang perlu dibagi satu dengan lainnya, 2) keterlibatan orang tua dalam program tidak hanya berjenti pada pendidikan anak, tetapi sebaiknya berlanjut sampai pada jenjang berikutnya, 3) Program yang disusun lembaga pendidikan melibatkan semua anggota keluarga, 4) program yang disusun lembaga pendidikan menjadikan tugas guru menjadi lebih mudah, dan 5) program berkembang seiring dengan waktu.

Menurut Briggs dan Potter (1995, dalam Suyanto (2005, hal.225) kerjasama orang tua dengan lembaga pendidikan dikelompokkan menjadi dua, yaitu: keterlibatan (parent involment) dan partisipasi (parent participation). Keterlibatan orang tua merupakan tingkat kerjasama yang minimum, misalnya orang tua datang ke lembaga pendidikan dan membantu lembaga pendidikan jika diundang saja. Sebaliknya partisipasi orang tua merupakan tingkat kerjasama yang lebih luas dan tinggi tingkatannya. Orangtua dan sekolah duduk bersama untuk membicarakan berbagai program dan kegiatan anak. Orangtua datang ke sekolah untuk membantu guru melaksanakan tugas-tugas rutin, seperti menyiapkan makanan, menyiapkan alat/media yang 
dibutuhkan untuk pembelajaran, dan ikut menjadi keamanan

Keterlibatan keluarga dalam kegiatan sekolah banyak sekali dampak positif bagi perkembangan anaknya. Hal ini didasarkan pada beberapa hasil penelitian yang diungkapkan dalam makalah seminar Teori, Kebijakan dan Praktek Pendidikan Keluarga di Indonesia (2012, hal. 3) sebagai berikut:

a. Hasil penelitian Izzo dkk (1999), dalam American Journal of Community Psychologi, menunjukkan bahwa ketika orang tua dan sekolah berkolaborasi secara efektif, siswa dapat berperilaku dan menunjukkan prestasi yang lebih baik di sekolah

b. Grenwood \& Hickman (dalam Gurbuzturk \& Sad, 2010) menyebutkan bahwa keterlibatan orang tua di sekolah memberikan kontribusi yang positif dalam prestasi akademis, frkuensi kehadiran anak, iklim sekolah, persepsi orang tua dan anak tentang belajar di kelas, sikap dan perilaku positif anak, kesiapan anak untuk mengerjakan PR, peningkatan waktu yang dihabiskan anak bersama orang tuanya, aspirasi pendidikan, kepuasan orang tua terhadap guru, dan kesadaran anak terhadap well being

c. Kotaman (dalam Gurbuzturk \& Sad, 2010) menjelaskan bahwa keterlibatan orang tua yang aktif dapat memberi efek positif pada berbagai aspek pendidikan termasuk meningkatkan perilaku anak dan adaptasi social, mengurangi masalah kedisiplinan di sekolah, meningkatkan kesuksesan di sekolah, dan peningkatan kehadiran di sekolah.

d. Studi dampak program pendidikan dan pengembangan anak usia dini di 50 kabupaten tertinggal (World Bank, 2013), menunjukkan bahwa intensitas dukungan keluarga berpengaruh meningkatkan pencapaian perkembangan anak usia dini (usia 0-6 tahun)

e. Kajian system pembinaan professional dan cara belajar siswa aktif (Harlen, et.all., 2001), menunjukkan bahwa kemitraan dan peran aktif orang tua di sekolah berpengaruh meningkatkan kemajuan dan kesuksesan anakanak mereka.

\section{Bentuk kemitraan keluarga dengan sekolah}

Kemitraan keluarga dengan sekolah dapat diwujudkan dalam berbagai bentuk, diantaranya yaitu melalui:

a. Kegiatan pertemuan orang tua Kelas orang tua merupakan wadah komunikasi bagi orang tua untuk saling berbagi informasi dan pengetahuan dalam melaksanakan pendidikan bagi anak-anaknya.

b. Keterlibatan orang tua di kelas anak

Keterlibatan orang tua di kelas adalah kegiatan yang melibatkan orang tua dalam bentuk: 1) bermain bersama anak di kelas, 2) membantu pendidik dalam proses pembelajaran di kelas, 3) 
memonitor pelaksanaan pembelajaran anak di kelas

c. Keterlibatan orang tua dalam acara bersama

Keterlibatan orang tua dalam acara bersama adalah kegiatan yang melibatkan orag tua dalam pelaksanaan kegiatan penunjang pembelajaran yang dilakukan di luar kelas. Tujuannya adalah mendekatkan hubungan antar orang tua dengan anak dan orang tua dengan sekolah

d. Hari konsultasi orang tua

Hari konsultasi orang tua adalah hari-hari tertentu yang dijadwalkan oleh pengelola sekolah untuk beryermu dengan orang tua. Konsultasi dapat dilakukan secara individual ataupun kelompok. Tujuannya adalah supaya orang tua memahami perkembangan anakanaknya, dan orang tua mengetahui untuk melakukan pendidikan di keluarga.

Contoh daftar keterlibatan keluarga dalam kegiatan di sekolah yang disosialisasikan oleh Kementerian Pendidikan dan Kebudayaan Direktorat Jenderal Pendidikan Anak Usia Dini dan Pendidikan Masyarakat Direktorat Pembinaan Pendidikan Keluarga yaitu:

a. Mengantar anak dan mengikuti pertemuan dengan wali kelas pada hari pertama masuk sekolah

b. Mengikuti pertemuan dengan wali kelas pada tengah semester

c. Mengikuti kelas orang tua pada semester Satu d. Mengambil rapor semester satu (konsultasi kemajuan anak

e. Mengikuti pertemuan dengan wali kelas pada awal semester dua

f. Mengikuti pertemuan dengan wali kelas pada tengah semester dua

g. Membahas persiapan pentas kelas akhir tahun bersama paguyuban orang tua

h. Menghadiri pentas kelas akhir tahun dan pemberian penghargaan kepada anak dan orang tua

i. Mengambil raport semester dua (konsultasi kemajuan anak)

Daftar dukungan keluarga di rumah (Keluarga Anak usia PAUD dan SD

a. Membiasakan anak beribadah sesuai agama yang dianutnya

b. Membiasakan anak sarapan/makan sebelum berangkat sekolah

c. Membiasakan anak berpamitan sebelum berangkat sekolah

d. Memberikan aturan yang disepakati (misalnya memberi tahu jika pulang terlambat, jam belajar, waktu tidur)

e. Menyambut anak pulang sekolah

f. Menciptakan suasana aman dan nyaman di rumah

g. Menjadi pendengar yang baik bagi anak

h. Mendampingi anak saat menonton acara televise

i. Membiasakan hidup sehat dan bersih

j. Mendongeng atau membackan cerita bagi anak

k. Melakukan kegiatan bersama anak (ibadah, olah rag, rekreasi)

1. Dalam mendidik anak tidak menggunakan kekarasn 


\section{SIMPULAN DAN REKOMENDASI}

Pendidikan merupakan tanggung jawab bersama antara keluarga, sekolah dan pemerintah. Untuk mewujudkan hal tersebut perlu adanya kemitraan antara sekolah dan keluarga, karena: 1) Keluarga adalah pendidik yang pertama dan utama, tetapi dalam praktiknya masih banyak keluarga yang menyerahkan sepenuhnya tanggung jawab pendidikan anak pada sekolah, 2) Peran sekolah adalah membantu keluarga agar pelaksanaan pendidikan lebih sistimatis, efektif, dan hasilnya tersertifikasi, 3) Tidak semua kebutuhan pendidikan anak dapat dipenuhi oleh satuan pendidikan maupun keluarga, 4) Kerjasama keluarga dengan satuan pendidikan mutlak diperlukan, 5) Satuan pendidikan wajib mendorong kemitraan dan pelibatan keluarga dalam memajukan pendidikan anak mereka.

Bentuk kemitraan antara sekolah dengan keluarga dapat dilakukan melalui: 1) kegiatan pertemuan orang tua, 2) keterlibatan orang tua orang tua di dalam kelas anak 3) keterlibatan orang tua dalam acara bersama, 4) Hari konsultasi anak.

Dampak adanya kolaborasi antara sekolah dengan keluarga adalah:: 1) siswa dapat berperilaku dan menunjukkan prestasi yang lebih baik di sekolah, 2) memberikan kontribusi yang positif dalam prestasi akademis, frkuensi kehadiran anak, iklim sekolah, persepsi orang tua dan anak tentang belajar di kelas, sikap dan perilaku positif anak, kesiapan anak untuk mengerjakan PR, peningkatan waktu yang dihabiskan anak bersama orang tuanya, aspirasi pendidikan, kepuasan orang tua terhadap guru, dan kesadaran anak terhadap well being, 3) memberi efek positif pada berbagai aspek pendidikan termasuk meningkatkan perilaku anak dan adaptasi social, mengurangi masalah kedisiplinan di sekolah, meningkatkan kesuksesan di sekolah, dan peningkatan kehadiran di sekolah, 4) intensitas dukungan keluarga berpengaruh meningkatkan pencapaian perkembangan anak usia dini (usia 0-6 tahun), 5) kemitraan dan peran aktif orang tua di sekolah berpengaruh meningkatkan kemajuan dan kesuksesan anak-anak mereka.

\section{DAFTAR REFERENSI}

Berger, E.H. (1991). Parent as Partners in Education. New York: Mac Millian Publishing Company.

Brewer, J. (2007). Introduction to Early Childhood Education. Preschool Through Primary Ade Grades. New York: Pearson.

Brooks, J, ((2011). The Process of Parenting.Yogyakarta: Pustaka Pelajar.

Megawangi, R. (2003) Pendidikan Karakter untuk Membangun Masyarakat Madani. IPPK Indonesia Heritage Foundation.

Raraswati, P. (2016. Makalah Kebijakan Pembinaaan Pendidikan Keluarga. Kementerian Pendidikan dan Kebudayaan, Direktorat Jenderal PAUD dan PENMAS, PP-PAUD dan DIKMAS Jawa Barat.

Riana, dkk. (2012). Pendidikan Keorangtuaan dan Keluarga di Indonesia. Bandung: Pusat Pengembangan Anak Usia Dini Nonformal dan Informal Regional I Bandung.

Suyanto, S. (2005). Konsep Dasar Pendidikan Anak Usia Dini. Jakarta: 
PEDAGOGIA : Jurnal Ilmu Pendidikan

Direktorat Pembinaan Pendidikan Tenaga

Kependidikan dan Ketenagaan Perguruan Tinggi.
Undang-Undang Republik Indonesia No 20 tahun 2003 tentang Sistem Pendidikan Nasional. Bandung: Fokusmedia. 